\title{
Creativity and Intercultural Experiences: The Impact of University International Exchanges
}

\author{
Elena De Prada ${ }^{\mathrm{a}}$ \\ University of Vigo, Spain \\ E-mail address: edeprada@uvigo.es \\ Margarita Pino-Juste ${ }^{c}$ \\ University of Vigo, Spain \\ E-mail address: mpino@uvigo.es
}

\author{
Mercedes Mareque ${ }^{b}$ \\ University of Vigo, Spain \\ E-mail address: chedesmareque @uvigo.es
}

\section{ARTICLE INFO}

\author{
Keywords: \\ Creativity \\ Multiculturalism \\ Intercultural experiences \\ Interculturality \\ Foreign language proficiency \\ Higher education
}

\section{A B S TRACT}

Based on recent findings that highlight the strong links between creativity and interculturality, we will attempt to establish a relationship between intercultural experiences and creativity within the context of international university exchanges in order to propose specific courses of action for improving these skills. The methodology used is based on a quasiexperimental design for a sample of 303 university students from a Spanish university. Data were obtained from a survey that measured creativity with two different instruments (RIBS-s and Divergent Thinking), English proficiency, and intercultural experiences abroad. Results show a strong relationship between creativity and intercultural experiences, suggesting that those students who lived abroad and in a higher number of foreign countries are more creative. Additionally, the most significant differences appear when we establish a comparison between those students who have not lived abroad and those who have done so in more countries, which contributes to highlighting the close relationship between interculturality and creativity. Of special significance is the strong link found between English proficiency and having experiences abroad, suggesting that when the level of a shared international language, English in this case, is higher, there will be more options to increase students' creativity. Likewise, students who have a higher level of English are more creative. Designing programs for higher education students that combine and integrate foreign language skills, creativity, and interculturality appear to be essential. Thanks to foreign language skills, students will be in a better position to acquire intercultural sensitivity and improve their creativity, making their international experience a valued source of fulfilment both for their personal life and their career.

\footnotetext{
${ }^{a}$ Faculty of Business and Tourism, Campus Universitario, s/n - 32004 Ourense, Spain. University of Vigo. ORCID iD (0000-0002-8207-2459).

${ }^{\mathrm{b}}$ Faculty of Business and Tourism, Campus Universitario, s/n - 32004 Ourense, Spain. University of Vigo. ORCID iD (0000-0001-8927-5323).

${ }^{c}$ Faculty of Education Sciences and Sports, Campus A Xunqueira, s/n - 36005 Pontevedra, Spain. University of Vigo. ORCID iD (0000-0002-2551-5903).
} 


\section{INTRODUCTION}

One of the main objectives of universities nowadays is to try to meet the increasingly demanding requirements of the work market and, for this reason, academic boards are concentrating their efforts on designing syllabuses that include the specific skills that leading companies demand. Innovation and internationalization have become a must in most institutions and companies (Cassiman \& Golovko 2011) and, accordingly, both creativity and multiculturalism have become essential skills for a successful professional career. In this context, employers prefer to hire creative (Ortiz, Region-Sebest, \& MacDermott, 2016; Wesley, Jackson, \& Lee, 2017) and internationally experienced graduates with good intercultural and communication skills (Bennet \& Kane, 2011; Jones, 2013). As a consequence, studying abroad becomes an important factor for easier integration into the job market (Di Pietro, 2015).

Different researchers have emphasised the need for higher education institutions to use all their resources to offer students specific training in these competencies. Some studies have shown that intercultural skills can be effectively taught (Maddux, Adam, \& Galinsky, 2010), providing students with the necessary knowledge to ascertain the ways to manage multicultural perspectives (Tadmor \& Tetlock, 2006) for the development of creativity. However, teaching creativity has proved to be far from easy (Kaufman, 2018). Accordingly, including intercultural competencies in university syllabuses (Jones, 2013; Lyubovnikova, Napiersky, \& Vlachopoulos, 2015) can be a suitable option to improve creativity in an indirect way. Therefore, seeking ways to channel acquisition of both creativity and interculturality must be a priority in higher education, as their interrelationship can yield very important benefits for students (Dewaele, 2016; Lee, Therriault, \& Linderholm, 2012).

Consequently, the main objective of this paper is to attempt to establish the relationship between multicultural experiences and creativity, and to delve deeper into those factors related to intercultural features that can favor creative potential. Based on the resulting findings, we intend to propose specific courses of action for improvement of these skills. In the present study, interculturality will be considered within the context of higher education international exchanges that require a minimum stay of a semester abroad.

Regarding the methodology used, this study has applied two complementary instruments in an attempt to overcome the difficulties of measuring and evaluating creativity (Sternberg \& Lubart, 1999). The first one was designed to measure creative potential and is called the Runco Ideational Behavior Scale (RIBS). The other instrument measures divergent thinking (DT) and is in the form of a construct that includes three criteria or indicators (originality, fluency and flexibility). 


\section{Theoretical background and hypotheses}

Creativity is one of the most complex processes in human beings, so identifying its configuration is a highly challenging task. One of the first researchers in this area, Guilford (1962), claimed that creative individuals have certain divergent thinking (DT) skills, such as ideational fluency, flexibility, or original thinking. Along the same lines, Wallach and Kogan (1965) define creativity as generation of abundant (fluency) and unique (originality) ideas. Other authors, such as Amabile (1983), Kachelmeier, Reichert and Williamson (2008), or Rogers (1959) define creativity as production of unique and useful products, services, processes, or procedures. Research into creativity has sprung from various areas, including education, although, despite its importance, university education is the least studied area (Cheung, Rudowicz, Yue, \& Kwan, 2003; Fitó-Bertran, Hernández-Lara, \& Serradell-López, 2014).

Grasping the concept of interculturality has also been the subject of debate for researchers from different disciplines, as it includes the notion of culture, approached under the scope of diverse ideologies (Jackson, 2018). For our purposes, we will be positioned within the conceptual framework and methodology of interculturality in education, specifically in international education (Knight, 2004; Jackson, 2018). Multiculturalism has been defined as recognition, acceptance, and tolerance of other cultures, conveying peaceful sharing of common space. Interculturality goes a step further, as it incorporates dialogue and interaction, proactively sharing knowledge and values through communication (Gumucio-Dagron, 2014). Importantly, effective intercultural communication requires an interculturally sensitive attitude and cultural knowledge (Nunez, Nunez, \& Popma, 2017). As we will see in what follows, some features associated with interculturality have shown to have a deeper impact on creativity.

Recent studies seem to be unanimous in their attribution of a decisive role of multicultural experiences in the development of creativity (Crisp \& Turner, 2011; Ghonsooly \& Showqi, 2012; Lee et al., 2012; Leung, Maddux, Galinsky, \& Chiu, 2008), although one should bear in mind a series of clarifications that condition the relation between culture and creativity to a large extent. First, it is crucial to take into account the fact that culture helps individuals in a group to coordinate their social behavior, routines and knowledge, while on the other hand, it has a levelling effect that limits creative potential (Leung et al., 2008). One's own culture creates feelings of confidence and identity in the individual, thus making them feel comfortable and adapted. However, it may simultaneously hinder generation of new ideas because of the routinized responses it causes (Ip, Chen, \& Chiu, 2006).

In contrast, when an individual is immersed in a different cultural context, while they may initially experience culture shock, the new surroundings will open up a world full of 
new perspectives that can help tackle different tasks and challenges and teach new ways of thinking. In this way, although culture may constitute a limitation for creativity, multicultural experience has the opposite effect and may contribute to creative development (Leung et al., 2008). Thanks to exposure to multiple cultures, individuals will not only generate new ideas (Leung \& Chiu, 2010; Maddux \& Galinsky, 2009), but they will be more prepared to establish different connections among different ideas and approach problems using different perspectives as well (Leung et al., 2008). Therefore, being in contact with different cultures can be a powerful stimulus to ignite people's creativity and lead them to question previous assumptions as well as to view reality in a different light, as their familiar cultural context may conflict with the new environment (Tadmor \& Tetlock, 2006). This cultural clash and the process of adaptation it conveys may bring about a significant change in different cognitive features associated with creative thinking (Leung \& Chiu, 2010; Tadmor, Tetlock, \& Peng, 2009). Nevertheless, as previous research has pointed out, not all multicultural experiences have the same positive impact on creativity. It is necessary to take into account the considerations that follow.

According to the studies carried out, one needs to live abroad (not simply visit the country) for there to be a positive and long-lasting effect on creativity (Maddux \& Galinsky, 2009). Exposure to various cultures is not only the best predictor of intercultural communication skills (Williams, 2005), but to creativity as well: its impact will be especially relevant when one lives in different countries (Kim, 2016). Living in a foreign country offers many opportunities and motivations for cognitive and behavioural change and adaptation, neither common nor necessary during short-term travel (Leung et al., 2008). Even while living abroad, this multicultural experience needs to go hand-in-hand with an open attitude on the part of individuals to increase their creative potential. Multiculturalism is not a guarantee of creativity, unless the individual is willing to broaden their horizons and experiences (Leung et al., 2008).

It has similarly been pointed out that in order to stimulate the creative process, the two cultures need to be cohabitated simultaneously (Leung \& Chiu, 2008), since living abroad demands both integration and identification with the new culture and adherence to one's own. Various studies have stated that this bicultural integration fosters creativity and creative entrepreneurship (Maddux, Leung, Chiu, \& Galinsky, 2009). Likewise, some studies emphasise that multicultural exposures are not enough to enhance creative thinking: interactions must take place (Aytug, Rua, Brazeal, Almaraz, \& González, 2018).

It is important to note that living abroad and interculturality are also related to other experiences or changes that naturally occur in this situation, such as the undergoing ad- 
aptation to new surroundings in terms of different languages, cultural knowledge, values, norms expected behaviour and beliefs. Individuals in contact with different cultures will have to decide when to activate different worldviews and how to integrate them (Tadmor \& Tetlock, 2006) in order to foster development of creativity. An adequate way to overcome these difficulties is through training. In this way, intercultural learning becomes a critical component in the process of adaptation, acting as a catalyst in increasing creativity (Maddux et al., 2010).

It is essential to consider the relationship between the knowledge of a common language of communication (English in this study) and those aspects deeply linked to interculturality, such as integration, interaction, and adaptation that, according to different studies, favor creative development (Leung et al. 2008; Leung \& Chiu, 2008; Maddux et al. 2009; Aytug et al., 2018). Research has shown that proficiency in the host or common language facilitates becoming more open to interculturality (Hernández, 2010). Likewise, it has been mentioned that lack of language skills in international students can lead to frustration, discomfort, and disorientation (Jackson, 2018). Students with limited foreign language skills report being confused and uncomfortable when abroad (Berdan, 2015), which causes them stress (Savicki, 2012), foreign language anxiety (Horwitz, Horwitz, \& Cope, 1986), and culture shock (Weaver, 1993). Studies from different fields have concluded that we must consider the strong relationship between creativity and foreign language proficiency (Albert \& Kormos, 2011; Nosratinia \& Zaker, 2014). A particularly relevant point concerning multilingualism and creativity is that, in addition to other related factors that might contribute to explain this link, the intercultural experiences associated with the communicative situation have shown to play a significant role (Kharkhurin, 2012, 2017). Higher education exchange programs constitute ideal contextual frameworks that involve intermingling of the features mentioned above. They facilitate living and getting integrated into a foreign country. Very frequently, universities allow enrolling in various exchange programs in different academic years and countries, thus contributing to increase students' opportunities for creative development (Kim, 2016). Accordingly, we will consider that international students and, by extension, the subjects of our study, will theoretically meet the criteria that, according to research, are required for creativity development: positive attitude, adaptation, integration-identification, and interactions (Leung et al., 2008; Leung \& Chiu, 2008; Maddux et al., 2009; Aytug et al., 2018). Therefore, based on the results of the existing literature described above, we put forward the following hypotheses: Hypothesis 1. There is a relationship between English proficiency and stays abroad. Hypothesis 2. Students with a higher level in English will be more creative. 
Hypothesis 3. Students will be more creative if they have lived abroad.

Hypothesis 4. Students will be more creative if they have lived in a number of different countries.

\section{METHOD}

\section{Participants}

The study was carried out at the Universidad de Vigo, located in Galicia (Spain). The sample was made up of 303 students (127 male and 176 female). The average age was 21, and the standard deviation 3.29.

\section{Instrument and Procedure}

There are different considerations in literature regarding the type of instruments that measure creativity, with divergent thinking tests being most frequently used in all their variations (Runco \& Acar, 2012). Nevertheless, given that many authors consider these tests to be insufficient in the measurement of such a complex construct as creativity, two different measures have been applied; on the one hand, the Runco Ideational Behaviour Scale (RIBS), which measures creative potential, and on the other, a construct of three components that measure divergent thinking (DT: originality, fluency, and flexibility). As it has been pointed out "highly creative individuals can generate ideas at a fast rate (fluency), go against the norm in order to tackle problems from a new perspective (flexibility) and come up with new and truly different ideas (originality)" Guilford (1971).

Creative potential (RIBS) was assessed with "Everyday" creativity scale from the Runco Ideational Behaviour Scale (Runco, Plucker, \& Lim, 2001). The RIBS measures how often respondents generate new ideas in their daily lives and has proven to have a right level of reliability in various earlier studies (Runco et al., 2001; Runco et al., 2014), as well as good construct validity, discriminant validity (Runco et al., 2001), and concurrent validity (Runco et al., 2014). The Everyday Creativity RIBS scale we have used is based on the "Runco Ideational Behaviour Scale: short form" (RIBS-s), which has a high correlation with the original RIBS. Given that the RIBS-S is easier to administer and has the same validity as the original RIBS, it is the most expedient measure (Runco et al., 2014). The questionnaire given to the participants to measure their creative potential has 19 items to be answered according to a 5-point Likert scale: (1) never, (2) yearly, (3) monthly, (4) weekly, and (5) daily.

The measures of divergent thinking (Beketayev \& Runco, 2016; Runco, 1986; Wallach \& Kogan, 1965) are structured in three parts containing nine questions and ask the participants to do the following: (1) give alternative titles for a selection of films (Titanic, Romeo and Juliet, Harry Potter); (2) name as many applications they can think of for 
a series of products and services (rubbish bin, car steering wheel, computer mouse); (3) interpret the meaning of three schematic illustrations. The answers were scored based on the following components: (1) Originality: The number of unique answers compared to the other answers in the sample (Runco, 1986).(2) Fluency: Total number of answers (Wallach \& Kogan, 1965). (3) Flexibility: The number of different categories used (Beketayev \& Runco, 2016).

Individual scores for originality, fluency, and flexibility were calculated. The results for the divergent thinking task represent the overall performance across all tasks. All the categories (originality, fluency, and flexibility) contribute to divergent thinking. Ideas were analyzed using a computer algorithm. In order to corroborate the reliability of the measurement scale, Cronbach's alpha coefficient was calculated.

Originality and fluency gave a coefficient greater than 0.86 , while creative potential (RIBS-s) was over 0.74 ; this implies that reliability in the first two cases is high, being moderate in the third case (Gliem \& Gliem, 2003; Sijtsma, 2009). As far as flexibility is concerned, most of the DT tasks analyzed with this instrument have been administered in English. As most answers in the present study were in Spanish and were translated to English, we have been unable to determine its reliability score, since this is based on a semantic analysis of English words (Beketayev \& Runco, 2016). At the current moment, the research on semantic analysis of Spanish sentences is not as reliable as the one for English (Beketayev \& Runco, 2016). Originality and fluency have been rated independently in both languages. The questionnaire was made up of three parts:

(1) Foreign language knowledge. English was considered the common language of communication (academic and social). To assess students' level of English as a foreign language, we used their perception according to the European Framework (A1C2). This type of measurement (self-perception of level) is used by other studies such as those by Dewaele and Stavans (2014), Fürst and Grin (2018) and Korzilius, Van Hooft, Planken and Hendrikx (2011) who highlight the fact that this measurement has greater validity than their academic marks or other objective measurements in many situations.

(2) Multicultural experience. Two types of measures were obtained:

- Whether respondents had lived abroad.

The type of international exchanges analyzed require a minimum stay of one semester.

- The number of countries in which they had lived.

Erasmus+, ISEP and other international exchange programs allow students to experience different programs in diverse countries. Our university does not limit the number of exchanges abroad. 
(3) Creativity: It includes 28 questions, 19 of which measure creative potential (RIBS-s) and the other nine divergent thinking (originality, fluency and flexibility). The distribution for creative thinking (RIBS-s) is normal $(p>.05)$, while the measures for divergent thinking (originality, fluency, and flexibility) are not $(p=.0001)$. Therefore, we shall use the T student for the RIBS-s for dichotomous variables and the Anova test for polytomous variables. For the measures of divergent thinking (originality, fluency, and flexibility), we shall use Kruskal-Wallis and the Mann-Whitney $U$ test in order to establish the relationship between the dichotomous and polytomous variables, respectively. The Pearson correlation will be used in the first case for the scale variables and the Spearman-Brown correlation in the second.

A significance level of 0.05 was assumed in all the contrasts carried out. Data analysis was performed via the SPSS statistical package (version 22). The questionnaire could be completed in a preferred language (Spanish or English).

\section{RESULTS}

Considering the results for all the subjects of the sample, as shown in Table 1 below, creative potential (RIBS-s) scored relatively high and is close to the maximum score. The measures for divergent thinking (originality, fluency, and flexibility) have low scores. Creative potential (RIBS-s) has negative skewness and kurtosis; this implies that the distribution tail is longer for values below the mean and lower than the mode. In contrast, the measures for divergent thinking have positive skewness and kurtosis; thus, the distribution is longer for values above the mean, and higher than the mode.

Table 1

Descriptive Statistics

\begin{tabular}{lccccrrr}
\hline & N & Min & Max & Mean & SD & Skewness & Kurtosis \\
\hline RIBS-s & 303 & 35 & 86 & 60.77 & 9.492 & -.051 & -.451 \\
Originality & 303 & 0 & 62 & 13.56 & 9.539 & 1.441 & 3.754 \\
Fluency & 303 & 0 & 77 & 19.60 & 13.264 & 1.040 & 1.688 \\
Flexibility & 303 & 0 & 28 & 5.89 & 5.439 & 1.505 & 2.328 \\
\hline
\end{tabular}

Regarding Hypothesis 1, results show that there is a significant relationship between the level of English as a foreign language and having lived in a foreign country. Students with a lower level of English are those who have not stayed abroad. Furthermore, there is a higher number of students with B2-C2 level among those who have lived abroad. Likewise, students who have had more life experiences abroad in different countries have a higher command of English as a foreign language (Table 2). Consequently, hypothesis 1 is accepted. 
Table 2

Chi-square test as a function of perception of English knowledge

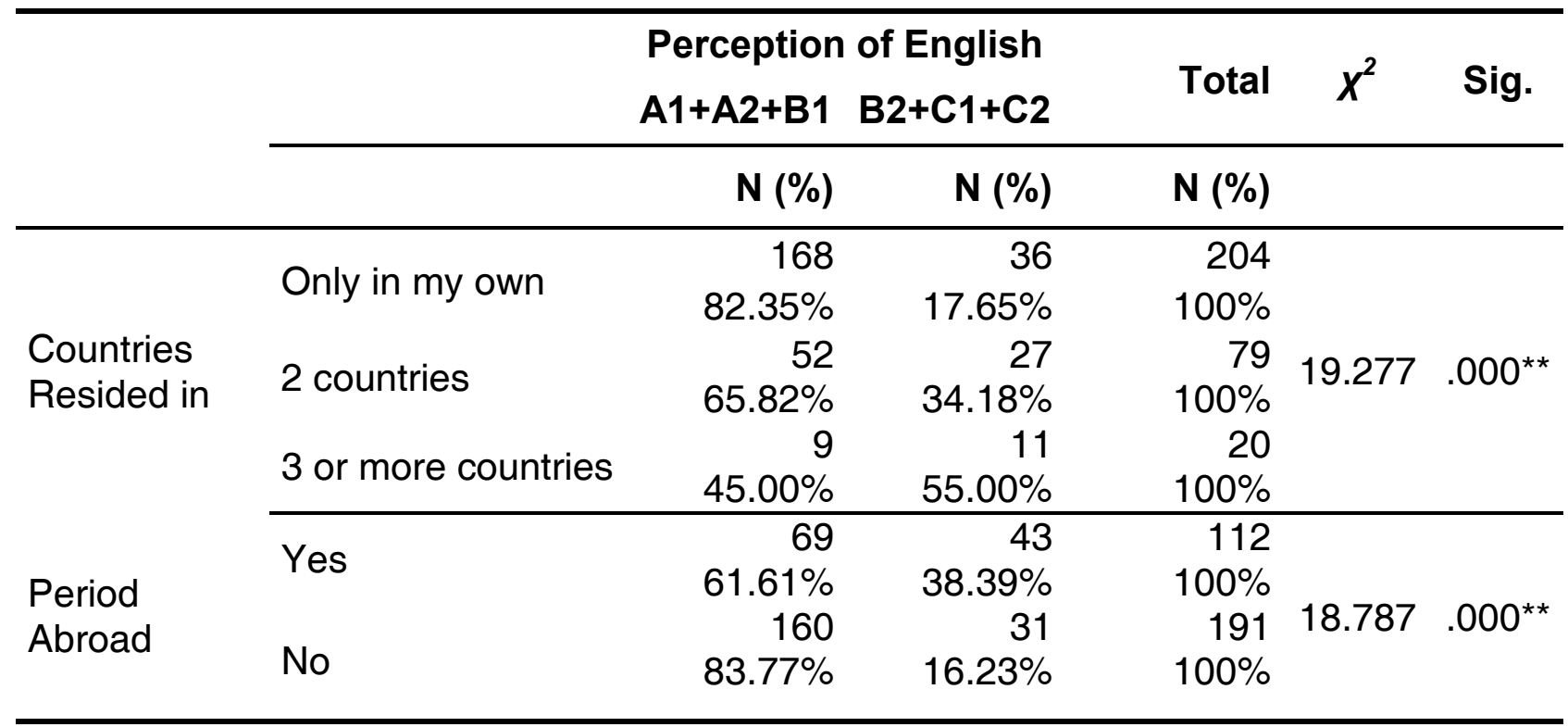

Note: $\mathrm{N}=303 ;{ }^{* \star} \mathrm{p}<.01$

Hypothesis 2, which tried to establish a relationship between proficiency in English and creativity, is also confirmed. Results indicate that the students with higher selfperception of the level of English $(\mathrm{B} 2+\mathrm{C} 1+\mathrm{C} 2)$ obtained a greater average range for both creativity measures, with a significant relationship between language learning and creative potential (RIBS-s). Table 3 below shows the results.

Table 3

T-Student test for creative potential based on self-perception of their level of English

\begin{tabular}{llllllllll}
\hline & $\begin{array}{l}\text { Perception } \\
\text { of English }\end{array}$ & $\mathbf{N}$ & Mean & SD & $\mathbf{F}$ & Sig. & $\mathbf{t}$ & Bilateral Sig. \\
\hline RIBS-s & A1+A2+B1 & 229 & 60.05 & .987 & & & & \\
& B2+C1+C2 & 74 & 62.99 & 1.00 & & & & & \\
\hline
\end{tabular}

$\mathrm{N}=303 ;{ }^{*} \mathrm{p}<.05$

Hypothesis 3 is accepted for the three components of divergent thinking. The students who lived abroad are more creative as a result, see Table 4 below. Regarding creative potential (RIBS-s), students who lived abroad obtained a greater average range. 


\section{Table 4}

Mann-Whitney $\mathrm{U}$ test for the components of divergent thinking based on living experiences abroad

\begin{tabular}{llllll}
\hline & $\begin{array}{c}\text { Period } \\
\text { Abroad }\end{array}$ & N & $\begin{array}{c}\text { Average } \\
\text { range }\end{array}$ & $\begin{array}{l}\text { Sum of } \\
\text { ranges }\end{array}$ & Sig. \\
\hline \multirow{2}{*}{ Originality } & Yes & 112 & 169.85 & 19023.00 & $.007^{\star *}$ \\
& No & 191 & 141.53 & 27033.00 & \\
\hline \multirow{2}{*}{ Fluency } & Yes & 112 & 165.07 & 18488.00 & $.047^{*}$ \\
& No & 191 & 144.34 & 27568.00 & \\
\hline \multirow{2}{*}{ Flexibility } & Yes & 112 & 172.27 & 19294.00 & $.002^{\star *}$ \\
& No & 191 & 140.12 & 26762.00 & \\
\hline
\end{tabular}

Note: $\mathrm{N}=303 ;{ }^{* *} \mathrm{p}<.01$

Hypothesis 4 is accepted for both measures of creativity, implying that the students who have lived in a higher number of foreign countries are more creative than those who have not or who have visited fewer countries. Furthermore, after applying the Bonferroni test, it was observed that greater differences appear between not having lived abroad and having done so in three or more countries (Tables 5 and 6). As we can see, the higher the students' number of countries of residence, the higher the creative potential (RIBSs) and degree of originality, flexibility and fluency (Tables 5 and 6).

Table 5

Anova test for creative potential based on the number of countries of residence

\begin{tabular}{|c|c|c|c|c|c|c|}
\hline & $\begin{array}{l}\text { Number of } \\
\text { Countries }\end{array}$ & $\mathbf{N}$ & Mean & $\mathbf{F}$ & Sig. & Bonferroni \\
\hline \multirow{3}{*}{ RIBS-s } & Only in my own & 204 & 59.97 & \multirow{3}{*}{4.966} & \multirow{3}{*}{$.008^{* *}$} & \multirow{3}{*}{$\begin{array}{l}\text { Only in my own and in } 3 \text { or } \\
\text { more countries } p=.007^{\star *}\end{array}$} \\
\hline & 2 countries & 79 & 61.33 & & & \\
\hline & 3 or more countries & 20 & 66.75 & & & \\
\hline
\end{tabular}

Note: $\mathrm{N}=303 ;{ }^{*} \mathrm{p}<.05,{ }^{* *} \mathrm{p}<.01$ 


\section{Table 6}

\section{Kruskal-Wallis $\mathrm{H}$ test for the components of divergent thinking based on the number of countries of residence.}

\begin{tabular}{|c|c|c|c|c|c|}
\hline & Countries of residence & $\mathbf{N}$ & Average range & Chi-squared & Sig. \\
\hline & Only in my own & 204 & 143.20 & & \\
\hline \multirow[t]{3}{*}{ Originality } & 2 countries & 79 & 161.45 & 10.175 & $.006^{\star *}$ \\
\hline & 3 or more countries & 20 & 204.48 & & \\
\hline & Only in my own & 204 & 145.00 & & \\
\hline \multirow[t]{3}{*}{ Fluency } & 2 countries & 79 & 158.25 & 7.380 & $.025^{\star *}$ \\
\hline & 3 or more countries & 20 & 198.65 & & \\
\hline & Only in my own & 204 & 143.66 & & \\
\hline \multirow[t]{2}{*}{ Flexibility } & 2 countries & 79 & 163.91 & 7.121 & $.028^{* *}$ \\
\hline & 3 or more countries & 20 & 189.98 & & \\
\hline
\end{tabular}

Note: $\mathrm{N}=303 ;{ }^{* *} \mathrm{p}<.01$

\section{DISCUSSION}

As we saw, multiple studies show the common benefits obtained through the relationship between interculturality and creativity in different contexts and situations. In our specific case, the results obtained are in line with previous work focused on university students and exchange programs (Dewaele, 2016; Lee et al., 2012). The results also reveal important information about the creative profile and multicultural experience of this sample of university students, and clearly reinforce the idea of the importance of a sound knowledge of a common language of communication and of the link between interculturality and creativity.

The creative potential index (RIBS-s) of the sample made up of university students is relatively high, while it drops in the measures of divergent thinking (originality, flexibility, and fluency). It is therefore necessary to increase their creativity in global terms. However, as we described in the previous section, and we will analyze in what follows, differences in creativity can be observed depending on students' experiences abroad. The different factors that have been associated with successful intercultural experiences can take place within the context of students' exchanges, which have provided very promising results regarding improvement of creative skills.

In terms of proficiency in foreign languages, we can observe two interesting facts. Firstly, students who have different experiences abroad have a higher command of English as a foreign language and, secondly, students with a higher self-perception of lan- 
guage skills in English obtained a greater average range for both creativity measures, with a significant relationship between language learning and creative potential (RIBS-s). The relationship found between a higher level of English and experiences abroad suggests that students are in an optimum condition for an adequate adaptation, integration and possibility of interaction. Regarding the relationship between creativity and language proficiency, we can corroborate previous research on the subject in different situations (Albert \& Kormos, 2011; Fürst \& Grin, 2018; Ghonsooly \& Showqi, 2012; Nosratinia \& Zaker, 2014).

Studies also confirm that international students fully recognize that language proficiency is fundamental in their exchange experience and it is the most frequently mentioned aspect for a successful experience abroad (Van Maele, Vassilicos, \& Borghetti, 2016). Conversely, lack of language proficiency can be a problem, and some studies suggest that a limited command of English as a foreign language can put students in a disadvantaged position (Fortuijn, 2002). The students themselves are well aware of this limitation, as the study of Kondakci, Van den Broeck and Yildirim (2008) corroborates, and they feel confusion (Berdan, 2015) and frustration (Jackson, 2018), which impedes their opportunities to adapt and integrate. Language skills will also condition the possibility of establishing interactions and students will frequently find a linguistic barrier, caused either by the students' low level of English or the lack of knowledge of the language spoken in the country (Kondakci et al., 2008). Accordingly, language proficiency proves to be a necessary constituent for intercultural and creative development, but, as we will see, it is not the only one.

Regarding interculturality and how this affects creativity, we can observe that having lived abroad signifies having crossed the limits that one's own culture may impose, motivating development of creative ideas (Leung \& Chiu, 2008). In fact, the results obtained firmly demonstrate that having the experience of living abroad has a very positive impact on the three components of creativity analyzed here (originality, fluency, and flexibility), and additionally on creative potential (RIBS-S) when the number of countries of residence is higher. That is, the greater the number of intercultural experiences, the greater the creativity in all analyzed aspects. This result is in line with numerous studies (Kim, 2009, 2016; Lee et al., 2012; Leung et al., 2008; Saad, Damian, Benet-Martínez, Moons, \& Robins, 2013).

As far as a positive attitude is concerned, it is important to note that university exchange students show favorable attitude towards other cultures and enjoy getting to know both the local culture and the cultures of other international students (Van der Beek \& Van Aart, 2014). Additionally, in theory, exchange students meet the conditions that so- 
cial psychology studies show as fostering mutual understanding, solidarity, and cooperation (De Federico, 2008). This favorable attitude that facilitates adaptation can be better acquired when students receive specific training (Thomas \& Waugh, 2020). Adaptation has also been considered an essential element for the development of creativity (Tadmor \& Tetlock, 2006). However, some studies have suggested that international students tend to fail in their adaptation to the host environments, which places them in a disadvantaged position (Ledwith \& Seymour, 2001; MacKinnon \& Manathunga, 2003). This situation is especially relevant if their skills in the common communication language are limited (Fortujin, 2020; Kondakci et al., 2008). All the factors mentioned so far will condition the amount and quality of interactions, a fundamental ingredient to facilitate intercultural skills and creativity. Interactions with students, both in academic and informal contexts, proved to be beneficial for students' acquisition of global, international, and intercultural competencies (Soria \& Troisi, 2014).

Regarding integration, international students normally combine spending time with locals, compatriots, and people from different nationalities and cultural backgrounds, so integration with the new culture/s and identification with their own take place within the exchange structure. Friendship with other international students helps them get much input about intercultural differences, which is a valuable asset. They make lots of friends and create new networks. Erasmus experience produces great intercultural contact during and after the exchange (De Federico, 2008). This connection and understanding of the different cultures involved will produce a more sophisticated way of looking at the world (Dwyer, 2004).

However, it is also true that some research on student mobility suggests that the relationships established between the host communities and exchange students are frequently limited and sometimes adverse (Ayano, 2006; Kondakci et al. 2008; Opper, Teichler, \& Carlson, 1990). If the conditions are not favorable, there is a risk that students get immersed in an "international students-only" or even worse "compatriots-only" sort of ghetto. If this happens, all the advantages that could be gained thanks to the otherwise beneficial structure of international exchanges can fade away. To improve this situation and facilitate integration and interactions, specific training about intercultural sensitivity can be a determining factor (Nunez et al., 2017).

Applying these considerations to the present study, we can contribute to existing literature by indicating that our results suggest that even if students may find some difficulties of adaptation and integration to the new environment, the result of the experience is clearly beneficial in terms of creative development. This finding implies that the intercul- 
tural experience has been successful, especially for students with good communication skills. As we highlighted previously, research indicates that for creativity to be fostered, intercultural exchanges must have a specific set of features, such as positive attitude, adaptation-identification, and interaction, which the subjects of our study have acquired, at least to some extent. Those attempts of adaptation and desire to overcome possible problems can lead to creative behaviour, as mentioned (Leung et al., 2008).

\section{Implications for University Education}

These results are very encouraging from the perspective of education and the current exchange programs around the world (Erasmus, ISEP, among others), since benefits related to the development of creativity can be added to those numerous advantages associated with this type of experience (linguistic and academic, among others). Compared to staying on campus, international exchanges are highly favorable for university students to acquire intercultural skills, as research has widely pointed out (Paige, Cohen, \& Shively, 2004; Williams, 2005), even if it is for a short time (Anderson, Lawton, Rexeisen, \& Hubbard, 2006; Chieffo \& Griffiths, 2004). Furthermore, the impact of studying abroad can be sustained for a long time after arrival in the home country (Dwyer, 2004). When students get integrated into an international exchange program for a whole semester or more, the effects can be even more beneficial and, if the intercultural exchange meets the conditions described in the previous sections, students will also improve their creative potential.

However, the exchange experience should meet several conditions to be entirely successful. Regarding relevance of adaptation, integration, and interaction, it is crucial to minimize the negative effect that could be caused by groups of friends moving to the same destination for social reasons. These students will not focus on understanding or overcoming cultural differences and would, therefore, gain less benefit from the experiences abroad (Chapdelaine \& Alexitch, 2004; Van-Dyne, Ang, \& Koh, 2008). This issue could be countered if the destination university makes an effort to mix local and international students in accommodation, courses, and extracurricular activities (Holtbrügge \& Engelhard, 2016). It would thus fall on the destination universities to reverse this situation that is unsuitable in terms of interculturality, language learning and, ultimately, creativity.

The importance of being proficient in a common communication language has also been demonstrated (Kondakci et al., 2008). A good command of English as an international language (B2 and higher) should be required for international exchanges to facilitate interaction and integration and will, accordingly, have a more profound impact on creativity. Very few universities include this requirement in their admission process, so sending institutions should foster acquisition of a foreign language or improving of English skills before departure (Holtbrügge \& Engelhard, 2016). 
While intercultural experience is related to improving creative performance (Crisp \& Turner, 2011; Leung et al., 2008), it is essential to note that living abroad is not the only way to access the benefits derived from intercultural experiences (Chang, Hsu, Shih, \& Chen, 2014). Individuals can gain multicultural experiences through other types of multicultural interactions, even in their own country. Interacting with peers from other foreign countries and cultures can be a good example here. In this way, the intercultural situations that students can experience as a result of living abroad can be complemented with other encounters acquired in their own country of origin. Facilitating interactions and socialization between incoming and local students, organizing specific interactive and cooperative activities, such as international teamwork, joint seminars, or international weeks (Holtbrügge \& Engelhard, 2016; Leung \& Chiu, 2008) are but some examples. All these actions must have the purpose of promoting intercultural experiences, aimed at improving students' creativity. With this sort of complementary initiatives, creative learning can be a reality in academic contexts (Beghetto \& Karwowski, 2018). Working in groups that include members from different cultural backgrounds has also shown to have a positive impact on creativity (McLeod, Lobel, \& Cox Jr, 1996; Paulus, van der Zee, \& Kenworthy, 2016).

Increasing awareness of the importance of intercultural competence for students, academics, institutions, and employers can contribute to students' efforts to gain a better understanding of the value of international mobility and an internationalized curriculum at home. Additionally, awareness and understanding of other cultural manifestations have a positive effect on creativity (Maddux et al., 2010). Accordingly, specific training on interculturality has been considered to be highly advisable and convenient, due to its importance for acquiring intercultural competence (Nunez et al., 2017). Thus, inclusion of specific courses prior to departure may help students to integrate into intercultural situations better and, in turn, have their creative development strengthened.

For this purpose, it could be convenient to include teaching intercultural skills in university syllabuses, using either traditional, formal methods, such as lectures or lecturerled tutorials (Biggs \& Tang, 2007; Morton, 2010) or informal learning processes, such as immersion or experiential reflection (Chick, 1990). Devising and using courses and learning methods that combine language, creative, and intercultural skills can be an excellent option (Crozet \& Liddicoat, 1999). Equally, specific approaches to training in intercultural competencies can be a source of creative outcomes (Deardorff, 2020; Dziedziewicz, Gajda, \& Karwowski, 2014; Groyecka, et al., 2020). At the same time, this newly charged creativity can generate other beneficial outcomes (Kaufman, 2018) linked to the multicultural context, making creativity helpful for acquisition of different traits and skills, such as 
tolerance (Groyecka, 2019), openness to interactions, and integration. In this way, multiculturalism and creativity can form a powerful combination to enrich students' personal, academic and professional life.

Although there is limited evidence, some authors consider that it is quite likely that interculturalization of the curriculum in domestic settings can offer an important opportunity for acquisition of intercultural skills and all the benefits they convey (Jones, 2013; Soria \& Troisi, 2014). Universities should endeavour to replicate on campus most of the situations that lead to the benefits that can be accrued thanks to mobility experiences. Organizing international academic and extra-academic initiatives that foster socialization and interactions on campus could help students to increase their intercultural awareness and explore other viewpoints. Equally, devising activities and projects that require multicultural teamwork and cooperation could contribute to enriching both incoming and local students' academic experiences and improve their intercultural and creative skills.

\section{Limitations and Further Research}

The above study has certain limitations, which we address below. Regarding foreign language proficiency and participation in international exchanges, it is important to note that there might be other factors that could contribute to explaining why some students manage to acquire more advanced language skills (Dörney \& Skehan, 2003; Ellis, 2004; Skehan, 2014). Different personality and emotional factors that have been associated with successful language acquisition might also be playing an essential role in creative development. Likewise, deciding to leave their comfort zone and embarking on a new experience might also be involving some personality traits more responsive to creativity improvement. Additionally, the profile of students that have better English skills and participate in international exchanges might be representing a sort of educational and cultural élite. They could benefit from this capital and follow a more successful trajectory, not only regarding their creativity but other aspects as well.

More experimental studies that delve deeper into the relationship between interculturality and creativity could help to increase our knowledge about the various aspects that come into play and contribute to taking firmly grounded decisions in the education context. Further research on this relationship in different countries and contexts would help to justify the need for adapted policies and to design effective programs aimed at increasing and fostering intercultural and creative skills. Additional studies should be carried out with incoming, outgoing, and local students in both domestic and international settings. Having a more in-depth and extensive knowledge of the impact of this found interrelationship would help a lot to improve university competence training and maximize the benefits of international programs. 


\section{CONCLUSION}

We have corroborated that international exchanges can play a significant role in university training; apart from increasing students' linguistic ability, they also promote development of intercultural skills and creativity. Striving to recreate this positive interaction at home by increasing opportunities for contact and interaction with incoming international students can be equally as useful when reinforcing intercultural training. Involvement of the teaching center and staff in programming the tasks and activities that foster interculturality and creative thinking plays a fundamental role if this evident interrelation between both competencies is to be fully developed. If universities promote residential experiences abroad within the framework of exchange programs and aim to integrate international and local students, this could enrich our education system enormously, given that a student who is well-prepared in multiculturalism and has a creative spirit will be incorporated into the work market far more effectively. In addition, they will become an invaluable agent for any type of company with international projection.

International exchange programs will be most effective if students have a good language level of a common language and get previous training in intercultural sensitivity. Only in this way can interaction and integration be guaranteed, and students will be in an adequate position to improve their skills in intercultural sensitivity and creativity. Thanks to foreign language skills, students will be in a better position to acquire intercultural sensitivity and improve their creativity, making their international experience a valued source of fulfilment both for their personal life and their career.

\section{REFERENCES}

Albert, A., \& Kormos, J. (2011). Creativity and narrative task performance: An exploratory study. Language Learning, 61, 73-99. https://doi.org/10.1111/j.1467-9922.2004.00256.x Amabile, T. M. (1983). The social psychology of creativity: a componential conceptualization. Journal of Personality and Social Psychology, 45(2), 357-376. https://doi.org/ 10.1037/0022-3514.45.2.357

Anderson, P. H., Lawton, L., Rexeisen, R. J., \& Hubbard, A. C. (2006). Short-term study abroad and intercultural sensitivity: A pilot study. International Journal of Intercultural Relations, 30(4), 457-469. https://doi.org/10.1016/j.ijintrel.2005.10.004

Ayano, M. (2006). Japanese students in Britain. In M. Byram and A. Feng (Eds.), Living and studying abroad: Research and practice, 12, pp. 11-37. Clevedon. Buffalo. Toronto: Multilingual Matters. 
Aytug, Z. G., Rua, T., Brazeal, D. V., Almaraz, J. A., \& González, C. B. (2018). A sociocultural approach to multicultural experience: Why interactions matter for creative thinking but exposures don't. International Journal of Intercultural Relations, 64, 2942. https://doi.org/10.1016/j.jintrel.2018.03.004

Beghetto, R. A., \& Karwowski, M. (2018). Educational Consequences of Creativity: A Creative Learning Perspective, Creativity. Theories - Research - Applications, 5(2), 146 154. https://doi.org/10.1515/ctra-2018-0011

Beketayev, K., \& Runco, M. A. (2016). Scoring divergent thinking tests by computer with a semantics-based algorithm. Europe's Journal of Psychology, 1(2), 210-220. https://doi.org/10.5964/ejop.v12i2.1127

Bennet, R., \& Kane, S. (2011). Internationalization of U.K. University Business Schools: a Survey of Current Practice. Journal of Studies in International Education, 15(4), 351-373.

Berdan, S. N. (2015). Study abroad could be so much better. The Chronicle of Higher Education, 61(31), 27.

Biggs, J., \& Tang, C. (2007). Teaching for quality learning at university. 3rd ed. Maidenhead: Open University Press.

Cassiman, B., \& Golovko, E. (2011). Innovation and internationalization through exports. Journal of International Business Studies, 42(1), 56-75. https://doi.org/10.1057/ jibs.2010.36

Chang, J-H., Hsu, C-C., Shih, N-H., \& Chen, H-C. (2014). Multicultural families and creative children. Journal of Cross-Cultural Psychology, 45(8), 1288-1296. https:// doi.org/10.1177/0022022114537556

Chapdelaine, R. F., \& Alexitch, L. (2004). Social skills difficulty: Model of culture shock for international graduate students. Journal of College Student Development, 45(2), 167-184. https://doi.org/10.1353/csd.2004.0021

Cheung, Ch.-K., Rudowicz, E., Yue, X., \& Kwan, A. S. F. (2003). Creativity of university students: what is the impact of field and year of study? Journal of Creative Behavior, 37(1), 42-63. https://doi.org/10.1002/j.2162-6057.2003.tb00825.x

Chick, J. K. (1990). Reflections on language, interaction, and context: Micro and macro issues. In D. Carbaugh (Ed.), Cultural Communication and Intercultural Contact, pp. 253-258. Hillsdale: Lawrence Erlbaum.

Chieffo, L., \& Griffiths, L. (2004). Large-scale assessment of student attitudes after a short-term study abroad program. Frontiers: The Interdisciplinary Journal of Study Abroad, 10, 165-177. 
Crisp, R. J., \& Turner, R. N. (2011). Cognitive adaptation to the experience of social and cultural diversity. Psychological Bulletin, 137(2), 242-266. https://doi.org/10.1037/a0021840

Crozet, C., \& Liddicoat, A. J. (1999). The challenge of intercultural language teaching: Engaging with culture in the classroom. Striving for the third place: Intercultural competence through language education, 113-125.

Deardorff, D. K. (2020). Manual for developing intercultural competencies: Story circles. UNESCO Publishing. Routledge.

De Federico, A. (2008). How do Erasmus students make friends? In S. Ehrenreich; G. Woodman, \& M. Perrefort, (Eds.). Stays abroad in secondary and higher education: Current research and practice, (pp. 89-103). Münster: Waxmann.

Di Pietro, G. (2015). Do study abroad programs enhance the employability of graduates? Education, Finance and Policy, 10(2), 223-243.

Dewaele, J-M. (2016). Multi-competence and personality. In V. Cook and L. Wei (Eds.), The Cambridge handbook of linguistic multi-competence, pp. 403-419. Cambridge: Cambridge University Press.

Dewaele, J. M., \& Stavans, A. (2014). The effect of immigration, acculturation and multicompetence on personality profiles of Israeli multilinguals. International Journal of Bilingualism, 18(3), 203-221. https://doi.org/10.1177/1367006912439941

Dörnyei, Z., \& Skehan, P. (2003). Individual differences in second language learning. In C. J. Doughty and M. H. Long (Eds.), The handbook of second language acquisition, pp. 589-630. Oxford: Blackwell.

Dwyer, M. M. (2004). More is better: The impact of study abroad program duration. Frontiers: The Interdisciplinary Journal of Study Abroad, 10, 151-163.

Dziedziewicz, D., Gajda, A., \& Karwowski, M. (2014). Developing children's intercultural competence and creativity. Thinking Skills and Creativity, 13, 32-42.

Ellis, R. (2004). Individual differences in second language learning. In A. Davis and C. Elder (Eds.), The handbook of applied linguistics, pp. 525-551. Oxford: Blackwell.

Fitó-Bertran, À., Hernández-Lara, A. B., \& Serradell-López, E. (2014). Comparing student competences in a face-to-face and online business game. Computers in Human Behavior, 30, 452-459. https://doi.org/10.1016/j.chb.2013.06.023

Fortuijn, J. D. (2002). Internationalising learning and teaching: a European experience. Journal of Geography in Higher Education, 26(3), 263-273. https:// doi.org/10.1080/0309826022000019855

Fürst, G., \& Grin, F. (2018). Multilingualism and creativity: A multivariate approach. Journal of Multilingual and Multicultural Development, 39(4), 341-355. https:// doi.org/10.1080/01434632.2017.1389948 
Ghonsooly, B., \& Showqi, S. (2012). The effects of foreign language learning on creativity. English Language Teaching, 5(4): 161-167. http://dx.doi.org/10.5539/elt.v5n4p161

Gliem, J., \& Gliem, R. (2003). Calculating, interpreting, and reporting Cronbach's Alpha reliability coefficient for Likert-type scales. Conference in Adult, Continuing and Community Education. Midwest Research to Practice. The Ohio State University, Columbus. Available from: http://www.ssnpstudents.com/wp/wp-content/ uploads/2015/02/Gliem-Gliem.pdf.

Groyecka, A. (2018). Will Becoming More Creative Make us More Tolerant? Creativity. Theories - Research - Applications, 5(2), 170-176. https://doi.org/10.1515/ctra2018-0015

Groyecka, A., Gajda, A., Jankowska, D. M., Sorokowski, P., \& Karwowski, M. (2020). On the benefits of thinking creatively: Why does creativity training strengthen intercultural sensitivity among children. Thinking Skills and Creativity, 37, 100693.

Guilford, J. P. (1962). Factors that aid and hinder creativity. Teachers College Record, 63, 380-392.

Guilford, J. P. (1971). Some misconceptions regarding measurement of creative talents. The Journal of Creative Behavior, 5(2), 77-87.

Gumucio-Dagron, A. (2014). Indigenous communication: From multiculturalism to interculturality. The handbook of development communication and social change, 108124. https://doi.org/10.1002/9781118505328.ch7

Hernández, T. A. (2010). The relationship among motivation, interaction, and the development of second language oral proficiency in a study-abroad context. The Modern Language Journal, 94(4), 600-617. https://doi.org/10.1111/j.1540-4781.2010.01053.x

Holtbrügge, D., \& Engelhard, F. (2016). Study abroad programs. Individual motivations, cultural intelligence, and the mediating role of cultural boundary spanning. The Academy of Management, Learning and Education, 15(3), 435-455. https:// doi.org/10.5465/amle.2015.0128

Horwitz, E. K., Horwitz, M. B., \& Cope, J. (1986). Foreign language classroom anxiety. The Modern Language Journal, 70, 125-132. https://doi.org/10.1111/ modl.1986.70.issue-2.

Ip, G. W. M., Chen, J., \& Chiu, C. Y. (2006). The relationship of promotion focus, need for cognitive closure, and categorical accessibility in American and Hong Kong Chinese university students. Journal of Creative Behavior, 40(3), 201-215. https:// doi.org/10.1002/j.2162-6057.2006.tb01273.x

Jackson, J. (2018). Interculturality in international education. New York: Routledge. 
Jones, E. (2013). Internationalization and employability: The role of intercultural experiences in the development of transferable skills. Public Money \& Management, 33(2), 95-104. https://doi.org/10.1080/09540962.2013.763416

Kaufman, J. C. (2018). Creativity's Need for Relevance in Research and Real Life: Let's Set a New Agenda for Positive Outcomes, Creativity. Theories - Research - Applications, 5(2), 124-137. https://doi.org/10.1515/ctra-2018-0008

Kachelmeier, S. J., Reichert, B. E., \& Williamson, M. G. (2008). Measuring and motivating quantity, creativity, or both. Journal of Accounting Research, 46(2), 341-373. https:// doi.org/10.1111/j.1475-679X.2008.00277.x

Kharkhurin, A. V. (2012). Multilingualism and creativity. Bristol: Multilingual Matters.

Kharkhurin, A. V. (2017). Language mediated concept activation in bilingual memory facilitates cognitive flexibility. Frontiers in Psychology, 8, 1067. https://doi.org/10. 3389/fpsyg.2017.01067

Kim, D. (2016). Role of cognitive flexibility in bilingualism and creativity. Unpublished Doctoral Dissertation. Athens, Georgia, USA: University of Georgia.

Kim, K. H. (2009). Cultural influence on creativity: The relationship between Asian culture (Confucianism) and creativity among Korean educators. The Journal of Creative Behavior, 43(2), 73-93. https://doi.org/10.1002/j.2162-6057.2009.tb01307.x

Knight, J. (2004). Internationalization remodeled: Definition, approaches, and rationales. Journal of Studies in International Education, 8(1), 5-31. https://doi.org/10. $1177 / 1028315303260832$

Kondakci, Y., Van den Broeck, H., \& Yildirim, A. (2008). The challenges of internationalization from foreign and local students' perspectives: The case of management school. Asia Pacific Education Review, 9(4), 448-463. https://doi.org/10.1007/ BF03025662

Korzilius, H., Van Hooft, A., Planken, V., \& Hendrikx, C. (2011). Birds of different feathers? The relationship between multicultural personality dimensions and foreign language mastery in business professionals working in a Dutch agricultural multinational. International Journal of Intercultural Relations, 35(5), 523-553. https:// doi.org/10.1016/j.ijintrel.2011.02.018

Lee, C. S., Therriault, D. J., \& Linderholm, T. (2012). On the cognitive benefits of cultural experience: Exploring the relationship between studying abroad and creative thinking. Applied Cognitive Psychology, 26(5), 768-778. https://doi.org/10.1002/acp.2857

Ledwith, S., \& Seymour, D. (2001). Home and away: Preparing students for multicultural management. International Journal of Human Resource Management, 12(8), 12921312. https://doi.org/10.1080/09585190110083802 
Leung, A. K. Y. \& Chiu, C. Y. (2008). Interactive effects of multicultural experiences and openness to experience on creative potential. Creativity Research Journal, 20(4), 376-382. https://doi.org/10.1080/10400410802391371

Leung, A. K. Y., \& Chiu, C. Y. (2010). Multicultural experience, idea receptiveness, and creativity. Journal of Cross-Cultural Psychology, 41(5-6), 723-741. https:// doi.org/10.1177/0022022110361707

Leung, A. K., Maddux, W. W., Galinsky, A. D., \& Chiu, C. (2008). Multicultural experience enhances creativity. The then and how. American Psychologist, 63(3), 169-181. https://doi.org/10.1037/0003-066X.63.3.169

Lyubovnikova, J., Napiersky, U., \& Vlachopoulos, P. (2015). How are task reflexivity and intercultural sensitivity related to the academic performance of MBA students? Studies in Higher Education, 40(9), 1694-1714. https://doi.org/10.1080/ 03075079.2014.894016

MacKinnon, D. \& Manathunga, C. (2003) Going global with assessment: What to do when the dominant culture's literacy drives assessment. Higher Education Research \& Development, 22(2), 131-144. https://doi.org/10.1080/07294360304110

Maddux, W. W., Adam, H. \& Galinsky, A. D. (2010). When in Rome . . learn why the romans do what they do: How multicultural learning experiences facilitate creativity. Personality and Social Psychology Bulletin, 36(6), 731-741. https://doi.org/10.1177/ 0146167210367786

Maddux, W. W., \& Galinsky, A. D. (2009). Cultural borders and mental barriers: The relationship between living abroad and creativity. Journal of Personality and Social Psychology, 96(5), 1047-1061. http://dx.doi.org/10.2139/ssrn.1021265

Maddux, W. W., Leung, K. Y., Chiu, C. Y., \& Galinsky, A. D. (2009). Toward a more complete understanding of the link between multicultural experience and creativity. American Psychologist, 64(2), 156-158. https://doi.org/10.1037/a0014941

McLeod, P. L., Lobel, S. A., \& Cox Jr, T. H. (1996). Ethnic diversity and creativity in small groups. Small Group Research, 27(2), 248-264. https://doi.org/10.1177/ 1046496496272003

Morton, A. (2010). Lecturing to large groups. In H. Fry, S. Ketteridge, and S. Marshall, (Eds.), A Handbook for Teaching and Learning in Higher Education, 3rd ed., pp. 58-71. Oxon: Routledge.

Nosratinia, M., \& Zaker, A. (2014). Metacognitive attributes and liberated progress: The association among second language learners' critical thinking, creativity, and autonomy. SAGE Open, 4(3), 1-10. https://doi.org/10.1177/2158244014547178 
Nunez, C., Nunez, R., \& Popma, L. (2017). Intercultural Sensitivity. Assen, The Netherlands: Koninklijke van Gorcum.

Opper, S., Teichler, U., \& Carlson, J. (1990). Impact of study abroad programmes on students and graduates. London: Jessica Kingsley Publishers.

Ortiz, L. A., Region-Sebest, M., \& MacDermott, C. (2016). Employer perceptions of oral communication competencies most valued in new hires as a factor in company success. Business and Professional Communication Quarterly, 79(3), 317-330. https:// doi.org/10.1177/2329490615624108

Paige, R. M., Cohen, A. D., \& Shively, R. L. (2004). Assessing the impact of a strategiesbased curriculum on language and culture learning abroad. Frontiers: The Interdisciplinary Journal of Study Abroad, 10, 253-276.

Paulus, P. B., van der Zee, K. I., \& Kenworthy, J. (2016). Cultural diversity and team creativity. In V. P. Glăveanu (Ed.), The Palgrave handbook of creativity and culture research, pp. 57-76. London: Palgrave Macmillan.

Rogers, C. R. (1959). Toward a theory of creativity. In H. H. Anderson (Ed.), Creativity and its cultivation (pp. 69-82). New York, NY: Harper \& Row.

Runco, M. A. (1986). Flexibility and originality in children's divergent thinking. The Journal of Psychology, 120(4), 345-352.

Runco, M. A., \& Acar, S. (2012). Divergent thinking as an indicator of creative potential. Creativity Research Journal, 24(1), 1-10. https://doi.org/10.1080/10400419.2012. 652929

Runco, M. A., Plucker, J. A., \& Lim, W. (2001). Development and psychometric integrity of a measure of ideational behavior. Creativity Research Journal, 13(3-4), 393-400. https://doi.org/10.1207/S15326934CRJ1334_16

Runco, M. A., Walczyk, J. J., Acar, S., Cowger, E. L., Simundson, M., \& Tripp, S. (2014). The incremental validity of a short form of the ideational behavior scale and usefulness of distractor, contraindicative, and lie scales. The Journal of Creative Behavior, 48(3), 185-197. https://doi.org/10.1002/jocb.47

Saad, C. S., Damian, R. I., Benet-Martínez, V. Moons, W. G., \& Robins, R. W. (2013). Multiculturalism and creativity: Effects of cultural context, bicultural identity, and ideational fluency. Social Psychological and Personality Science, 4(3), 369-375. https:// doi.org/10.1177/1948550612456560

Savicki, V. (2012). The psychology of student learning abroad. In V. Berg (Ed.), Student Learning Abroad, pp. 215-238. Sterling, VA: Stylus. 
Sijtsma, K. (2009). On the use, the misuse and the very limited of the Cronbach's Alpha. Psychometrika, 74(1), 107-120. https://doi.org/10.1007/s11336-008-9101-0

Skehan, P. (2014). Individual differences in second language learning. London: Routledge.

Soria, K. M., \& Troisi, J. (2014). Internationalization at home alternatives to study abroad: Implications for students' development of global, international, and intercultural competencies. Journal of Studies in International Education, 18(3), 261-280. https:// doi.org/10.1177/1028315313496572

Sternberg, R. J., \& Lubart, T. I. (1999). The concept of creativity: prospects and paradigms. Handbook of Creativity, 1, 3-15.

Tadmor, C. T., \& Tetlock, P. E. (2006). Biculturalism: A model of the effects of secondculture exposure on acculturation and integrative complexity. Journal of CrossCultural Psychology, 37(2), 173-190. https://doi.org/10.1177/0022022105284495

Tadmor, C. T., Tetlock, P. E., \& Peng, K. (2009). Acculturation strategies and integrative complexity: The cognitive implications of biculturalism. Journal of Cross-Cultural Psychology, 40(1), 105-139. https://doi.org/10.1177/0022022108326279

Thomas, R. S., \& Waugh, C. E. (2020). Effects of script-based communicative intervention on psychological and cultural adaptation in students abroad in second-language contexts. Intercultural Education, 31(2), 1-16. https://doi.org/10.1080/ 14675986.2019.1702295

Van Maele, J., Vassilicos, B. \& Borghetti, C. (2016). Mobile students' appraisals of keys to a successful stay abroad experience: Hints from the IEREST project. Language and Intercultural Communication 16(3), 384-401. https://doi.org/10.1080/ 14708477.2016.1168050

Van-Dyne, L., Ang, S. \& Koh, C. (2008). Development and validation of the CQS: The cultural intelligence scale. In S. Ang and L. Van Dyne (Eds.), Handbook on Cultural Intelligence: Theory, Measurement and Applications, pp. 16-38. New York: M.E. Sharpe.

Van der Beek, C., \& Van Aart, J. (2014). Key influencers of international student satisfaction in Europe. Eindhoven, The Netherlands: StudyPortals.

Wallach, M. A., \& Kogan, N. (1965). Modes of thinking in young children: A study of the creativity-intelligence distinction. Oxford, U.K.: Holt, Rinehart \& Winston, Inc.

Weaver, G. R. (1993). Understanding and coping with cross-cultural adjustment stress. In R. M. Paige (Ed.), Education for intercultural experience, pp. 137-168. California: Intercultural Press. 
Wesley, S. C., Jackson, V. P., \& Lee, M. (2017). The perceived importance of core soft skills between retailing and tourism management students, faculty and businesses. Employee Relations, 39(1), 79-99. https://doi.org/10.1108/ER-03-2016-0051

Willians, T. R. (2005). Exploring the impact of study abroad on students' intercultural communication skills: Adaptability and sensitivity. Journal of Studies in International Education, 9(4), 356-371. https://doi.org/10.1177/1028315305277681

Corresponding author at: Elena De Prada, University of Vigo, Campus Universitario 32004 Ourense. Spain

E-mail: edeprada@uvigo.es 